Research Papers, part of a Special Feature on Bird Conservation in the Boreal Forest: Is there a Case for Resilience?

\title{
Are Boreal Ovenbirds, Seiurus aurocapilla, More Prone to Move across Inhospitable Landscapes in Alberta's Boreal Mixedwood Forest than in Southern Québec's Temperate Deciduous Forest?
}

\section{La Paruline couronnée, Seiurus aurocapilla, est-elle plus encline à traverser des paysages inhospitaliers dans la forêt mixte boréale de l’Alberta que dans la forêt feuillue tempérée du sud du Québec?}

\author{
$\underline{\text { Marc Bélisle }}^{1}, \underline{\text { André Desrochers }}^{2}{ }^{\text {Jean-François Gobeil }}{ }^{3}$, and $\underline{\text { Marc-André Villard }}^{4}$
}

\begin{abstract}
Population life-history traits such as the propensity to move across inhospitable landscapes should be shaped by exposure to landscape structure over evolutionary time. Thus, birds that recently evolved in landscapes fragmented by natural disturbances such as fire would be expected to show greater behavioral and morphological vagility relative to conspecifics that evolved under less patchy landscapes shaped by fewer and finer-scaled disturbances, i.e., the resilience hypothesis. These predictions are not new, but they remain largely untested, even for well-studied taxa such as neotropical migrant birds. We combined two experimental translocation, i.e., homing, studies to test whether Ovenbird, Seiurus aurocapilla, from the historically dynamic boreal mixedwood forest of north-central Alberta $(n=55)$ is more vagile than Ovenbird from historically less dynamic deciduous forest of southern Québec $(n=89)$. We found no regional difference in either wing loading or the response of homing Ovenbird to landscape structure. Nevertheless, this study presents a heuristic framework that can advance the understanding of boreal landscape dynamics as an evolutionary force.
\end{abstract}

RÉSUMÉ. Les caractéristiques biologiques des populations, telles que la propension à traverser des paysages inhospitaliers, devraient être modelées par l'exposition à la structure du paysage au fil de l'évolution. Ainsi, on devrait s'attendre à ce que les oiseaux qui ont évolué récemment dans des paysages fragmentés par des perturbations naturelles, comme le feu, montrent une plus grande capacité comportementale et morphologique à se déplacer que les individus conspécifiques ayant évolué dans des paysages moins fragmentés, dans lesquels les perturbations sont moins fréquentes et à échelle plus fine. Cette hypothèse est celle de la résilience. Ces prédictions ne sont pas nouvelles, mais elles ont rarement été testées, même dans le cas de taxons bien étudiés comme les oiseaux migrateurs néotropicaux. Nous avons combiné deux études sur le comportement de retour au territoire afin de vérifier si les Parulines couronnées, Seiurus aurocapilla, de la forêt mixte boréale du centre-nord de l'Alberta $(n=55)$ - une forêt qui est historiquement dynamique - sont plus aptes à se déplacer que les Parulines couronnées de la forêt feuillue du sud du Québec - une forêt qui est historiquement moins dynamique $(n=89)$. Nous n'avons pas trouvé de différences régionales, ni pour la charge alaire ni pour l'effet de la structure du paysage sur le retour des parulines. Néanmoins, cette étude présente un cadre heuristique qui peut contribuer à la compréhension de la dynamique des paysages boréaux en tant que force évolutive.

Key Words: Alberta; field experiment; forest fragmentation; homing; landscape ecology; microevolution; movement; Quebec; Seiurus aurocapilla

${ }^{1}$ Canada Research Chair in Spatial and Landscape Ecology, Département de biologie, Université de Sherbrooke Sherbooke, QC J1K 2R1, ${ }^{2}$ Centre d'étude de la forêt, Faculté de foresterie et de géomatique, Université Laval, ${ }^{3}$ Canadian Wildlife Service, Environment Canada, ${ }^{4}$ Chaire de recherche du Canada en conservation des paysages, Département de biologie, Université de Moncton

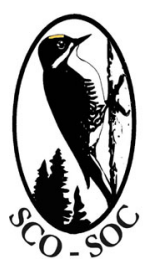

Sponsored by the Society of Canadian Ornithologists and Bird Studies Canada Parrainée par la Société des ornithologistes du Canada et Études d'oiseaux Canada

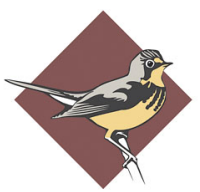

BIRD STUDIES CANADA 


\section{INTRODUCTION}

A tenet of natural disturbance emulation is that ecosystems and their associated species should be resilient to alterations closely reflecting the natural disturbance regime characteristic of the region (Mutch 1970, Bunnell 1995). Emulating natural disturbance has recently become standard management policy in several jurisdictions, although its underlying principle has rarely been tested (Perera et al. 2004). Such a test could take the form of a field experiment, whereby population parameters are compared between landscape units that are undergoing natural disturbances and others that are subjected to harvest prescriptions inspired by the same natural disturbances. One would expect populations to exhibit similar responses to both treatments and to return to their initial parameters at a similar rate. Alternatively, one might want to test the evolutionary mechanism underlying species resilience to disturbance. More specifically, the lifehistory traits that allow individuals from these populations to better tolerate anthropogenic disturbances should be more prevalent in populations experiencing intense natural disturbance regimes, i.e., with disturbances occurring at a high frequency and covering a vast extent, than in those inhabiting regions with lower-intensity natural disturbance regimes.

Many boreal forest regions are characterized by relatively frequent, extensive fires (Johnson 1992), which contrasts with forests of temperate regions (Lorimer 1977, Seymour et al. 2002). Such fires tend to create naturally patchy habitat mosaics (Payette et al. 1989, Smyth et al. 2005). In turn, these spatiotemporal dynamics may select for high vagility, i.e., the propensity to move, in animals or for various escape strategies in slow-moving or sessile organisms. Vagility in birds, even at the intraspecific level, can be inferred from morphological attributes, particularly wing shape (Alerstam 1990, Fiedler 2005). However, vagility is notoriously difficult to measure directly, except for in a minority of large-bodied species. Experimental translocations have been used as an index of vagility or landscape permeability in damselflies (Pither and Taylor 1998), frogs (Mazerolle and Desrochers 2005), passerine birds (Pärt 1995, Bélisle et al. 2001, Gobeil and Villard 2002), and small mammals (Bowman and Fahrig 2002, McDonald and St. Clair 2004). Territorial individuals are captured, moved over distances representing several territory diameters, and released. Observers then determine the time elapsed between release and return to the capture site. Although translocated individuals probably do not experience the same movement impulse as those that are displaced by natural disturbances or perform dispersal movements, we reason that experimental translocations can be used to assess the relative vagility of individuals between populations occupying landscapes with contrasting natural disturbance regimes.

Thus, we tested whether Ovenbird, Seiurus aurocapilla, is more vagile in the boreal mixedwood forest of north-central Alberta than in the temperate hardwood forest of southern Québec. We predicted that the wing loadings of Alberta Ovenbird would be lower than those of Québec Ovenbird, and that the speed of return of Ovenbird translocated in Alberta would be greater than that of Québec Ovenbird. We based our predictions on three assumptions. First, Alberta Ovenbird is geographically isolated from Québec conspecifics. Kelly and Hutto (2005) provide support for east-west demographic isolation in warblers, including Ovenbird. Second, movement costs incurred in the breeding grounds when seeking a territory, food, or mates, and when dispersing, are important enough to offset variations in movement costs caused by differences in migration routes among populations. Third, although fire return intervals typical of the boreal mixedwood forest are several times longer than the average lifetime of an individual Ovenbird, it seems reasonable to expect that since the last glaciation, Alberta Ovenbird has evolved in a more patchy landscape containing large burned areas with scattered unburned stands, whereas Ovenbird from the temperate forest of southern Québec has evolved in a landscape characterized by small, scattered, non-forest gaps such as small bogs, rocky outcrops, blowdowns, and treefall gaps. Because stands sometimes escape fire and reach old age even in the boreal mixedwood forest (Cumming et al. 2000), we assumed that mature and old stands were available to Ovenbird throughout the time period considered.

Admittedly, it is difficult to determine precisely the spatial patterns that have characterized disturbances over the past centuries in either region. Nevertheless, there is a clear difference in fire frequency between the boreal forests of Alberta and the hardwood forests found in the Québec City region. Contemporary Alberta fires tend to produce a mosaic of severely burned spruce or jackpine 
stands, with fewer fire-prone, poplar-dominated patches (Smyth et al. 2005 and references therein). Smyth et al. (2005) surveyed uplands similar to those occupied by Ovenbird and reported that, on average, live trees cover $26 \%$ of the area subject to wildfires. Cumming et al. (2000) have also documented the occurrence of gap-phase dynamics in the boreal mixedwood forest of Alberta, with gaps occupying $4-17 \%$ of stands surveyed. Thus, the natural disturbance regime of the boreal mixedwood forest does produce a structurally complex mosaic, but we submit that the coarse-grained structure created by fires in boreal Alberta cannot possibly be matched by the natural disturbance regimes that have characterized the Québec region in the recent or distant past. Indeed, widespread, stand-replacing disturbances like severe fire or windthrow were and are rare in the type of mixed-deciduous forests found in the latter area (Frelich and Lorimer 1991). For instance, Frelich and Lorimer (1991) estimated the average rates of disturbance or canopy mortality and gap formation at 5.7 to $6.9 \%$ per decade within primary forest tracts in Upper Michigan. Moreover, canopy residence times were estimated at 145-175 $\mathrm{yr}$, with a mixture of age classes in the stands, and even-aged stands were uncommon. Small, localized canopy gaps are the norm and do not cover more than $15 \%$ of the forest at any given time. It should be pointed out that in Alberta, Ovenbird mainly occupies closed-canopy, poplar-dominated stands (Schieck et al. 1995), which are relatively resistant to fire compared to stands that have a greater spruce component. The hypothesis that we examined emphasizes the legacy of natural disturbances on landscape structure, rather than the likelihood of local disturbance during the lifetime of an individual, but we acknowledge the need to control for contemporary landscape structure in interregional comparisons.

\section{METHODS}

\section{Study areas}

We compared data from two previous translocation experiments performed by Bélisle et al. (2001) and by Gobeil and Villard (2002). We conducted the former experiment in the temperate, northern hardwood forest of southern Québec, near Québec City $\left(46^{\circ} 45^{\prime} \mathrm{N}, 71^{\circ} 20^{\prime} \mathrm{W}\right)$, and the latter experiment in the boreal mixedwood forest of north-central Alberta, near Meanook (54 $\left.35^{\circ} \mathrm{N}, 113^{\circ} 26^{\prime} \mathrm{W}\right)$ and Owl River $\left(55^{\circ} 01^{\prime} \mathrm{N}, 111^{\circ} 89^{\prime} \mathrm{W}\right)$. In both experiments, we translocated Ovenbird individuals within landscapes that were either fragmented by agriculture (Québec, $n=89$; Meanook, $n=30$ ) or in naturally patchy forests interspersed with bogs and wet shrubby areas (Owl River, $n=25$ ). The regional forest cover was approximately $50 \%$ in Québec and 30\% and 80\% near Meanook and Owl River in Alberta, respectively. Rivers and lakes were uncommon in both study areas.

\section{Capture, measurement, and translocation}

We captured territorial male Ovenbird using mist nets and playbacks of their territorial songs and calls before 0800 standard time. For each individual, we measured body mass and wing length and fitted it with a unique combination of one metal and two colored bands to allow for individual recognition. We used wing chord in Alberta and flattened wing length in Québec. To correct for differences in measurement methods, we obtained both chord and flattened measures from 11 and 15 male Ovenbird skins from Alberta and Ontario, respectively (M. Gosselin, Canadian Museum of Nature). We based the corrections on the following regression model: flattened length $(\mathrm{mm})=6.36($ standard error $=6.57)$ $+0.93(0.09) \times$ chord $(\mathrm{mm})\left(r^{2}=0.83 ; n=26\right)$. This relationship did not vary between the provinces (model with chord, province, and chord $\times$ province vs. model with chord only: $\left.F_{2,22}=0.55, P=0.58\right)$.

After banding and measurement, we immediately moved individuals into a forest patch $>1$ ha that was located approximately $2 \mathrm{~km}$ away from the capture site, as determined using GPS coordinates and maps (Table 1). We chose release sites haphazardly given the constraints imposed by the road system, access in more remote areas, and landscape composition. Upon translocation, one observer continuously patrolled the territory of the released individual for $4 \mathrm{~h}$ while broadcasting playbacks of territorial calls and checking the legs of all Ovenbird individuals detected. When necessary, subsequent monitoring occasions (30 min/occasion) were conducted at 30 and $240 \mathrm{~h}$ post-translocation in Québec, and 24-30, 48 , and $168 \mathrm{~h}$ post-translocation in Alberta. Despite these differences, data were pooled because only one individual was first resighted after $30 \mathrm{~h}$ in Québec and none returned after $48 \mathrm{~h}$ in Alberta. Hence, it was possible to model homing times as a continuous variable between 0 and $4 \mathrm{~h}$, and as $30 \mathrm{~h}$ or $168 \mathrm{~h}$ for birds returning later. After $168 \mathrm{~h}$, homing times were considered to be censored cases. 
In Québec, censoring pertained to cases for which a bird did not return, whereas censoring in Alberta was mostly associated with cases for which the monitoring of a translocated bird had to be stopped before $168 \mathrm{~h}$. Thus, the proportion of birds that failed to return could not be based on the number of censored cases. However, this does not cause any bias when estimating return rates (Therneau and Grambsch 2000). All translocations were performed before fledging took place.

\section{Landscape characterization}

We described the composition, i.e., forest or nonforest, and configuration of the landscapes in which we translocated Ovenbird individuals based on two types of map. In the Québec experiment, we used Landsat-TM satellite images (pixels $=625 \mathrm{~m}^{2}$ ) taken in 1993-1994 and classified by the Canadian Wildlife Service (Bélanger and Grenier 2002). For the Alberta experiment, we characterized the Meanook study area using 1:40,000 aerial photographs that were classified, ground-truthed, and converted to a $225-\mathrm{m}^{2}$ pixel-resolution grid. The Owl River study area had already been characterized based on the interpretation of 1:15,000 aerial photographs and only had to be converted to $225-\mathrm{m}^{2}$ pixel-resolution grids. The pixel size differed between the two experiments, but this difference generally has no influence on landscape metrics up to a size of $640 \mathrm{~m}^{2}$ (Wickham and Riiters 1995). We defined forest and nonforest habitat patches as identical adjacent pixels, including diagonal contacts. We used Fragstats (McGarigal and Marks 1995) to measure the following landscape metrics: forest cover, forest patch density, mean forest patch size, total forest edge per forest cover area, total forest edge per landscape area, and mean nearest-neighbor distance among forest patches (Table 1). We chose these metrics because they are most likely to reflect the number and size of forest gaps encountered by birds, as well as the convolution of forest patches and the availability of fencerows, which can facilitate or impede movement depending on their orientation with respect to an individual's destination (reviewed in Bélisle and St. Clair 2001). To avoid including irrelevant information on landscape structure with respect to homing behavior and potential travel paths that linked the release and capture sites, we restricted the measurement of landscape metrics to an area delineated by the smallest rectangle into which we could fit an ellipse for which the foci corresponded to the capture and release sites and the eccentricity was 0.67 . We refer the reader to the original publications (Bélisle et al. 2001, Gobeil and Villard 2002) for further details.

\section{Model fitting and selection}

Because wing area could not be measured precisely in the field, wing loading was calculated as the ratio of body mass to wing length. We quantified the influence of explanatory variables on the wing loading index using generalized linear models that had an identity link and a normal random component. Because wing loading increases with body mass by allometry, we regressed $\log$ (wing loading) on $\log$ (body mass) following Chandler and Mulvihill (1992). We also considered the potential confounding effects associated with Julian date and the time of day at which birds were weighed when assessing the hypothesis that boreal Ovenbird exhibits lower wing loading than its temperate counterpart. This hypothesis was evaluated by comparing two models: one contained province as a main effect and one did not. Models were fitted using the $\operatorname{glm}()$ function of the stats library in the $\mathrm{R}$ statistical environment (v. 2.3.1; R Development Core Team 2006).

We modeled the influence of the explanatory variables on homing time rates using Cox proportional hazards regressions based on maximum partial likelihood estimates that were approximated using Efron's method (Therneau and Grambsch 2000). Such regressions quantify the influence of explanatory variables on the hazards of specific events; in our case, the event was that a bird returns to its territory. Hazards can be interpreted in terms of rates and expressed as the number of events per interval of time. Birds that did not return to their territories within $168 \mathrm{~h}$ were treated as singly, Type I, right-censored data (Therneau and Grambsch 2000). We fitted two models corresponding to our hypothesis, namely that boreal Ovenbird returns faster than temperate Ovenbird as a result of selection for greater vagility in dynamic boreal landscapes (Table 2). Both models contained translocation distance as an effect because birds that were moved over greater distances were expected to take longer to return. They also contained forest cover as an effect because this variable captured most of the influence of landscape structure on homing time in Bélisle et al. (2001) and Gobeil and 
Table 1. Regional comparison of Ovenbird body measurements and landscape structure. Means and standard deviations are shown.

\begin{tabular}{lcc}
\hline \hline Variable & Alberta $(n=55)$ & Québec $(n=89)$ \\
\hline Body mass $(\mathrm{g}) \dagger$ & $16.6 \pm 1.4$ & $19.2 \pm 1.2$ \\
Wing length (mm) $\ddagger$ & $77.9 \pm 2.2$ & $77.7 \pm 2.0$ \\
Wing chord (mm) from museum skins§ & $75.9 \pm 1.9$ & $76.2 \pm 1.6$ \\
Wing loading index (g/mm) & $0.21 \pm 0.02$ & $0.25 \pm 0.02$ \\
Homing time (h; uncensored cases) & $3.41 \pm 0.24$ & $2.47 \pm 0.85$ \\
Translocation distance (m) & $2039 \pm 337$ & $1870 \pm 428$ \\
Forest cover (\%) & $57.5 \pm 30.2$ & $55.2 \pm 28.4$ \\
Forest patch density (patches/km²) & $5.0 \pm 3.9$ & $1.9 \pm 1.5$ \\
Mean forest patch size (ha) & $55.9 \pm 72.7$ & $73.6 \pm 106.6$ \\
Forest edge / forest area (m/ha) & $171 \pm 112$ & $96 \pm 44$ \\
Forest edge / landscape area (m/ha) & $65 \pm 20$ & $42 \pm 12$ \\
Mean distance to nearest forest patch (m) & $41 \pm 13$ & $64 \pm 40$ \\
& & \\
\hline
\end{tabular}

$\dagger$ Uncorrected for date and time of capture; correction led to the same values.

\$Corrected for measurement method; see Methods for details.

§Alberta: $n=11$; Ontario: $n=15$.

Villard (2002). All of the landscape configuration variables were strongly correlated with forest cover; thus, they cannot convey much more information than forest cover itself once the forest cover variable is entered in a model. One of the two models contained the origin of the birds, i.e., Alberta vs. Québec, and its interaction with the amount of forest cover as effects. We included the latter interaction term because the effect of bird origin on vagility may vary with landscape composition, especially when forest cover is low. Homing time models were fitted using the $\operatorname{coxph}()$ function of the survival library in the R statistical environment (v. 2.3.1; R Development Core Team 2006).
For both wing loading and homing time, we assessed the weight of the evidence, i.e., the likelihood or $w_{\mathrm{i}}$, of each of the two models, i.e., hypotheses, to determine the best explanatory variables in their respective sets based on the corrected Akaike's Information Criterion $\left(\mathrm{AIC}_{\mathrm{c}}\right)$ and the adjusted $\mathrm{AIC}_{\mathrm{c}}$ $\left(\right.$ QAIC $_{c}$; Burnham and Anderson 2002). We present the evidence for or against a given hypothesis relative to its alternative using evidence ratios, whereby the likelihood of a model is divided by the likelihood of the alternative model, $w_{\mathrm{i}} / w_{\mathrm{j}}$ (Royall 1997, Burnham and Anderson 2002). We present model-averaged coefficients accompanied by their unconditional standard errors and confidence intervals as obtained by multimodel inference 
Table 2. Model selection assessing the influence of an Ovenbird's origin on wing loading and homing time of translocated individuals.

\begin{tabular}{l}
\hline \hline Model \\
\hline Wing loading
\end{tabular}

(Burnham and Anderson 2002). Unconditional standard errors and confidence intervals take into account model selection uncertainty.

\section{RESULTS}

The wing lengths of Ovenbird used in the experiments were very similar between Québec and Alberta $(95 \%$ confidence interval [CI] of the difference in means: -0.46 to $0.93 \mathrm{~mm}$; Table 1 ). However, the body mass of Ovenbird from Québec was about $15 \%$ higher than that of Ovenbird from Alberta $(95 \%$ CI of the difference in means after controlling for date and time of capture: 2.2-3.1 g), leading to an apparently greater wing loading for the Québec birds (Table 1). Nevertheless, when controlling for potential confounding factors, i.e., allometry and date and time of capture, there was no clear indication that the origin of the bird was an important predictor of wing loading (Table 2). Indeed, the model that contained the origin of the bird as a main effect was three times less likely to be the best model than the model that did not (Table 2). Moreover, the greater wing loading detected for the Québec birds was within measurement error, based on model-averaged regression coefficients (Table 3).

The composition of landscape units into which we translocated Ovenbird was similar between Québec and Alberta (Table 1). Forest cover ranged from 15.7 to $97.8 \%$ for the Québec landscapes and was 25.7-33.9\% and 82.3-98.0\% for landscapes located near Meanook and Owl River, Alberta, respectively. Although open areas were mostly agricultural near Meanook and natural, e.g., bogs, near Owl River, this discrepancy probably had a very low impact on our measures of large-scale vagility because natural open areas were restricted to landscapes that had very high forest cover. With respect to configuration, landscape units of the boreal mixedwood forest were slightly more fragmented than those of temperate, northern hardwood forest. This was indicated by greater forest patch density, smaller forest patches, and greater edge density 
Table 3. Multimodel inference based on the generalized linear models and the Cox proportional hazards regression models used to assess the influence of an Ovenbird's origin on log-transformed wing loading and homing time of translocated individuals, respectively.

\begin{tabular}{llcccc}
\hline \hline Response variable Explanatory variable & Coefficient & Standard error & \multicolumn{2}{c}{$95 \%$ confidence interval } \\
\cline { 4 - 5 } & & & & Lower bound & Upper bound \\
\hline Wing loading & Log(body mass [g]) & 0.955 & 0.359 & 0.251 & 1.660 \\
& Julian date & 0.0005 & 0.0003 & 0.0000 & 0.0011 \\
& Time of day (h) & 0.007 & 0.003 & 0.002 & 0.012 \\
& $\begin{array}{l}\text { Origin (reference: } \\
\text { temperate) }\end{array}$ & 0.014 & 0.001 & 0.001 & 0.026 \\
& Log(distance [m]) & -0.540 & 0.574 & -1.664 & 0.584 \\
& Forest cover (\%) & 0.011 & 0.005 & 0.000 & 0.021 \\
& $\begin{array}{l}\text { Origin (reference: } \\
\text { temperate) }\end{array}$ & 0.394 & 0.488 & -0.562 & 1.350 \\
& Forest cover $\times$ origin & -0.003 & 0.007 & -0.017 & 0.011 \\
& & & & \\
\hline
\end{tabular}

Note: Ovenbird individuals were translocated in the boreal mixedwood forest of north-central Alberta $(n=55)$ and in the temperate, northern hardwood forest of southern Québec $(n=89)$. Standard errors and confidence intervals are based on unconditional estimates of variance (sensu Burnham and Anderson 2002:162).

(Table 1). Such differences are partly the result of different land tenures, namely French seigneuries in Québec vs. English townships in Alberta. It is important to note that contemporary landscape differences and their origin apply to "experimental" landscapes and are very recent relative to those that characterized both regions when they were subjected only to natural disturbances.

The return times of Alberta and Québec Ovenbird were similar (Fig. 1). The model that contained origin (Alberta vs. Québec) was five times less likely to be the best model than the one that did not consider the origin of the bird as a predictor of homing time (Table 2). Furthermore, only the amount of forest cover influenced homing time (Table 3). According to regression estimates, the hazard of a bird returning to its territory increased by $1.06 \%$ for each $1 \%$ increase in forest cover. Thus, for example, a bird that is translocated within a landscape unit with $80 \%$ forest cover would be $89 \%$ more likely to return to its territory at any given point in time than would a bird that is translocated within a landscape unit with $20 \%$ forest cover.

\section{DISCUSSION}

We sought two lines of evidence, i.e., morphological and behavioral, to test whether the landscape disturbance regime represents a measurable evolutionary force for forest songbirds. On the morphological side, our results do not support the prediction that wing loading for Alberta Ovenbird is lower than that for Québec Ovenbird, 
Fig. 1. Cumulative return of translocated Ovenbird in the boreal mixedwood forest of north-central Alberta (red; $n=55$ ) and the temperate, northern hardwood forest of southern Québec (black; $n=89$ ). Values are based on Kaplan-Meier estimates.

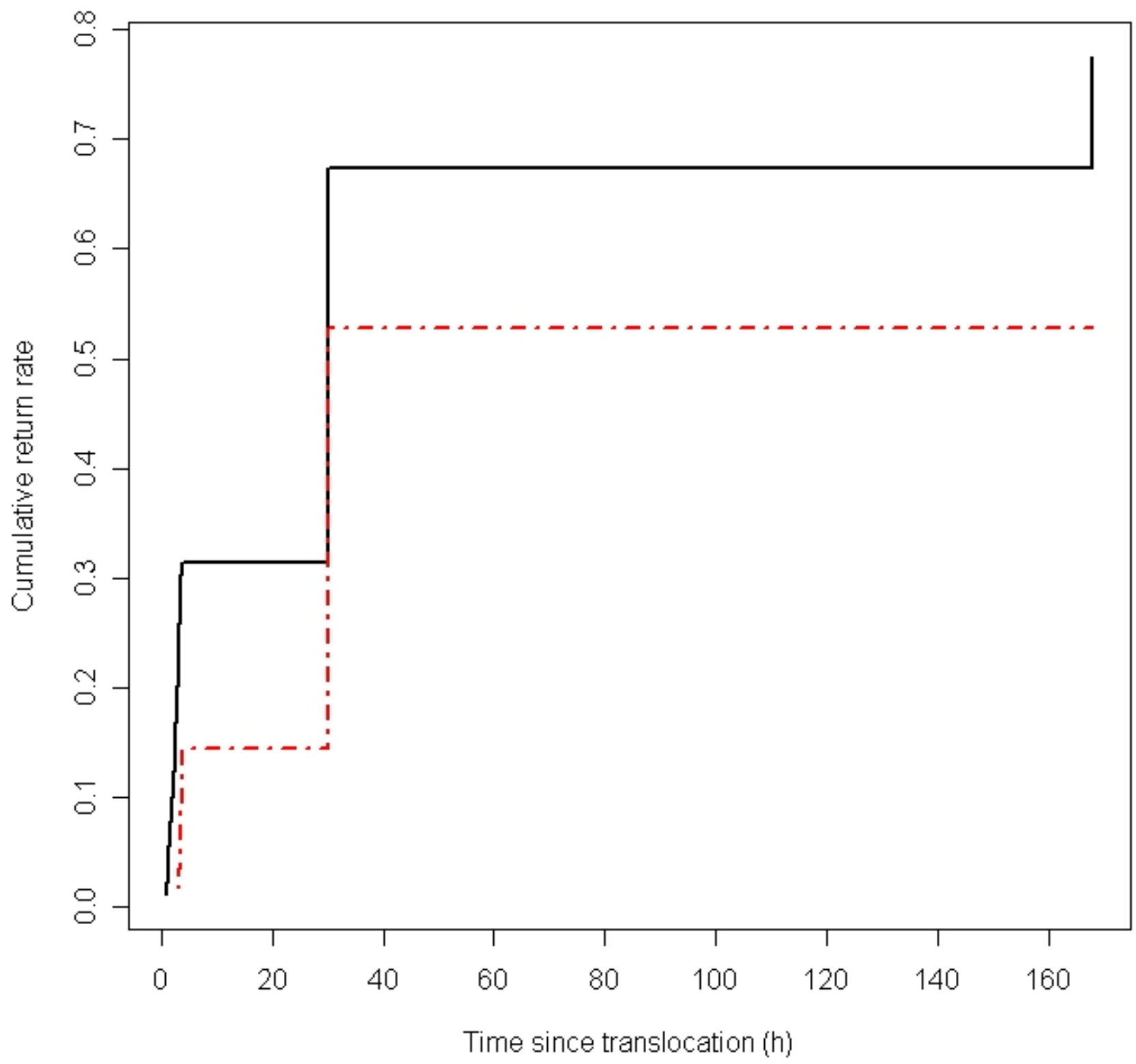


as would be expected from the hypothesized response to more dynamic Alberta landscapes. However, we cannot dismiss this prediction because the measurement of wing length alone may have failed to capture important differences in wing shape or area between the regions. On the behavioral side, our translocation results indicate no strong difference in the ability of Alberta vs. Québec Ovenbird to move quickly through landscapes, even though an evidence ratio of 4.9 against the model containing regional differences is insufficient to rule out the hypothesis (Royall 1997).

Could the challenges of migration facing Ovenbird exert a selective pressure on morphology and vagility so great that it would completely mask any adaptive response to landscape disturbance regimes? Answering this question is complicated by the fact that western populations of Ovenbird migrate over longer distances, i.e., to Mexico and Central America, than do eastern Ovenbird, i.e., to Florida and the Caribbean islands (Van Horn and Donovan 1994). A strong influence of migration should have been detectable, even with a fairly coarse measurement of wing loading such as wing length (e.g., Fiedler 2005), but it would have been in the same direction as the predicted effect of natural disturbance history. Indeed, when considering studies that show how much migratory birds move just before (Dale et al. 2005), during (Fraser and Stutchbury 2004, Dale et al. 2005), and immediately after (Vega Rivera et al. 2003) the breeding season, it could be argued that the cumulative cost of these small-scale movements (Hinsley 2000) may be sufficient to select for vagility, irrespective of adaptations pertaining strictly to migration (see Hedenström and Møller 1992). Thus, although the ability to successfully complete migration is a critical component of an individual's fitness, movements performed on the breeding grounds strongly influence an individual's ability to locate and exploit good-quality habitat and therefore, its reproductive performance. The fact that we found no difference in wing loading between the two populations seems to rule out both hypotheses.

Did the lack of strong regional differences in vagility actually reflect a lack of response to disturbance regimes, a lack of ecological isolation between Alberta and Québec populations, or simply evolutionary lag, i.e., insufficient time? A key assumption of our analysis is that the ecological isolation of Alberta Ovenbird from Québec
Ovenbird since the last glaciation, i.e., approximately $10,000 \mathrm{yr}$, has been sufficient to lead to measurable morphological and behavioral differences between these populations. This assumption is supported by recent analyses of migratory connectivity, which generally conclude that the winter ranges of western populations of North American warblers do not overlap much with the winter ranges of their eastern conspecifics (Kelly and Hutto 2005, Boulet et al. 2006). There is accumulating evidence for east-west genetic differences in species that have been studied to date (e.g., Boulet and Gibbs 2006). In the case of Ovenbird, eastern and northwestern populations belong to different subspecies (Van Horn and Donovan 1994). Given that our sample sizes were sufficient to reliably compare the merits of our competing models, we conclude that our results point to a limited or nonexistent role of the natural disturbance regime of forests in either determining the propensity for movement or influencing the morphology of Ovenbird.

To our knowledge, no previous study has tested for interpopulational differences in vagility. Thus, we have no yardstick against which to compare our translocation results. Furthermore, our comparison of disturbance regimes was unreplicated, thus opening the possibility for alternative hypotheses, e.g., possible influences of regional differences in Ovenbird population density and historical changes in the configuration of water bodies or river networks, among other effects. Conducting translocation experiments with Ovenbird at additional locations would probably not be of much benefit because the understanding of genetic isolation in Ovenbird is coarse at best. However, because our hypothesis is not specific to Ovenbird, it could be tested using a meta-analytic, comparative, and truly replicated approach to intraspecific regional differences in vagility using several forest specialists and looking for a general increase in vagility in landscapes with firedominated disturbance regimes. For such an exercise, it would be especially useful to select widespread species with well-documented polymorphism, e.g., subspecies, broadly corresponding to regions experiencing different disturbance regimes. 
Responses to this article can be read online at: http://www.ace-eco.org/vol2/iss2/art1/responses/

\section{Acknowledgments:}

We thank Michel Gosselin, Canadian Museum of Nature, who kindly provided wing chord and flattened wing length measurements from Ovenbird specimens. We also thank Bill Parsons for improving the English in this paper. This research was supported by grants from the Fonds québécois de la recherche sur la nature et les technologies $(M B)$, the Natural Sciences and Engineering Research Council of Canada (MB, AD, M-AV), as well as the Canada Research Chair in Spatial and Landscape Ecology (MB) and the Canada Research Chair in Landscape Conservation. Data for this paper originated from two experiments that were made possible through research grants and scholarships from the Canadian Wildlife Foundation $(J-F G)$, the Challenge Grants in Biodiversity program supported by the Alberta Conservation Association (J-FG), the Fonds québécois de la recherche sur la nature et les technologies (AD), the Natural Sciences and Engineering Research Council of Canada (MB, AD, M-AV), the Province of Quebec Society for the Protection of Birds $(M B)$, the Sustainable Forest Management Network (M-AV), and an NSERC/Alberta-Pacific Forest Industries Postgraduate Scholarship to J-FG.

\section{LITERATURE CITED}

Alerstam, T. 1990. Bird migration. Cambridge University Press, Cambridge, UK.

Bélanger, L., and M. Grenier. 2002. Agriculture intensification and forest fragmentation in the St. Lawrence valley, Quebec, Canada. Landscape Ecology 17:495-507.

Bélisle, M., A. Desrochers, and M.-J. Fortin. 2001. Influence of forest cover on the movements of forest birds: a homing experiment. Ecology 82:1893-1904.

Bélisle, M., and C. C. St. Clair. 2001. Cumulative effects of barriers on the movements of forest birds. Conservation Ecology 5: 9. [online] URL: http://w ww.consecol.org/vol5/iss2/art9.
Boulet, M., and H. L. Gibbs. 2006. Lineage origin and expansion of a Neotropical migrant songbird after recent glaciation events. Molecular Ecology 15:2505-2525.

Boulet, M., H. L. Gibbs, and K. A. Hobson. 2006. Integrated analysis of genetic, stable isotope, and banding data reveals migratory connectivity and flyways in the northern Yellow Warbler (Dendroica petechia; aestiva group). Ornithological Monographs 61:29-78.

Bowman, J., and L. Fahrig. 2002. Gap crossing by chipmunks: an experimental test of landscape connectivity. Canadian Journal of Zoology 80:1556-1561.

Bunnell, F. L. 1995. Forest-dwelling vertebrate faunas and natural fire regimes in British Columbia: patterns and implications for conservation. Conservation Biology 9:636-644.

Burnham, K.P., and D. R. Anderson. 2002. Model selection and multimodel inference: a practical information-theoretic approach. Second edition. Springer-Verlag, New York, New York, USA.

Chandler, C. R., and R.S. Mulvihill. 1992. Effects of age, sex, and fat level on wing loading in darkeyed juncos. Auk 109:235-241.

Cumming, S. G., F. K. A. Schmiegelow, and P. J. Burton. 2000. Gap dynamics in boreal aspen stands: is the forest older than we think? Ecological Applications 10:744-759.

Dale, S., A. Lunde, and Ø. Steifetten. 2005. Longer breeding dispersal than natal dispersal in the Ortolan Bunting. Behavioral Ecology 16:20-24.

Fiedler, W. 2005. Ecomorphology of the external flight apparatus of blackcaps (Sylvia atricapilla) with different migration behavior. Annals of the New York Academy of Sciences 1046:253-263.

Fraser, G. S., and B. J. M. Stutchbury. 2004. Areasensitive forest birds move extensively among forest patches. Biological Conservation 118:377-387.

Frelich, L. E., and C. G. Lorimer. 1991. Natural disturbance regimes in hemlock-hardwood forests of the upper Great Lakes region. Ecological Monographs 61:145-164. 
Gobeil, J.-F., and M.-A. Villard. 2002. Permeability of three boreal forest landscape types to bird movements as determined from experimental translocations. Oikos 98:447-458.

Hedenström, A., and A. P. Møller. 1992. Morphological adaptations to song flight in passerine birds - a comparative study. Proceedings of the Royal Society of London Series B 247:183-187.

Hinsley, S. A. 2000. The costs of multiple patch use by birds. Landscape Ecology 15:765-775.

Johnson, E.A. 1992. Fire and vegetation dynamics: studies from the North American boreal forest region. Cambridge University Press, Cambridge, UK.

Kelly, J. F., and R. L. Hutto. 2005. An east-west comparison of migration in North American wood warblers. Condor 107:197-211.

Lorimer, C. G. 1977. The presettlement forest and natural disturbance cycle of northeastern Maine. Ecology 58:139-148.

Mazerolle, M. J., and A. Desrochers. 2005. Landscape resistance to frog movements. Canadian Journal of Zoology 83:455-464.

McDonald, W. R., and C. C. St. Clair. 2004. The effects of artificial and natural barriers on the movement of small mammals in Banff National Park. Oikos 105:397-407.

McGarigal, K., and B. J. Marks. 1995. FRAGSTATS: spatial pattern analysis program for quantifying landscape structure. U.S. Forest Service General Technical Report PNW 351.

Mutch, R. W. 1970. Wildland fires and ecosystems —a hypothesis. Ecology 51:1046-1051.

Pärt, T. 1995. The importance of local familiarity and search costs for age- and sex-biased philopatry in the collared flycatcher. Animal Behavior 49:1029-1038.

Payette, S., C. Morneau, L. Sirois, and M. Desponts. 1989. Recent fire history of the northern Québec biomes. Ecology 70:656-673.
Perera, A. H., L. J. Buse, and M. G. Weber. 2004. Emulating natural forest landscape disturbances: concepts and applications. Columbia University Press, New York, New York, USA.

Pither, J., and P. D. Taylor. 1998. An experimental assessment of landscape connectivity. Oikos 83:166-174.

R Development Core Team. 2006. $R$ : a language and environment for statistical computing. $\mathrm{R}$ Foundation for Statistical Computing, Vienna, Austria. Available online at: http://www.r-project.org/

Royall, R. 1997. Statistical evidence: a likelihood paradigm. Chapman-Hall/CRC, New York, New York, USA.

Schieck, J., M. Nietfeld, and J. B. Stelfox. 1995. Differences in bird species richness and abundance among 3 successional stages of aspen-dominated boreal forests. Canadian Journal of Zoology 73:1417-1431.

Seymour, R. S., A. S. White, and P. G. deMaynadier. 2002. Natural disturbance regimes in northeastern North America-evaluating silvicultural systems using natural scales and frequencies. Forest Ecology and Management 155:357-367.

Smyth, C., J. Schieck, S. Boutin, and S. Wasel. 2005. Influence of stand size on pattern of live trees in mixedwood landscapes following wildfire. Forestry Chronicle 81:125-132.

Therneau, T. M., and P. M. Grambsch. 2000. Modeling survival data: extending the Cox model. Springer, New York, New York, USA.

Van Horn, M. A., and T. M. Donovan. 1994. Ovenbird. in A. Poole, P. Stettenheim, and F. Gill, editors. Birds of North America, Number 88. Academy of Natural Sciences, Philadelphia, Pennsylvania, USA. Available online at: http://bna. birds.cornell.edu/BNA/.

Vega Rivera, J. H., W. J. McShea, and J. H. Rappole. 2003. Comparison of breeding and postbreeding movements and habitat requirements for the Scarlet Tanager (Piranga olivacea) in Virginia. Auk 120:632-644. 
Wickham, J. D., and K. H. Riiters. 1995.

Sensitivity of landscape metrics to pixel size.

International Journal of Remote Sensing 16:3585-3594. 